\title{
Ecological Fluidizing Solvent for Road Bitumen Obtained by Pyrolysis of Mucilages Resulting from the Refining of Sunflower Oil
}

\author{
MIHAELA BOMBOS ${ }^{1}$, GABRIEL VASILIEVICI ${ }^{1 *}$, SANDA VELEA ${ }^{1}$, DORIN BOMBOS ${ }^{*}$ * \\ ${ }^{1}$ National Institute for Research Development for Chemistry and Petrochemistry- ICECHIM-Bucuresti, 202 Splaiul \\ Independentei, 060021, Bucharest, Romania \\ ${ }^{2}$ Petroleum-Gas University of Ploiesti, 39 Bucuresti Blvd., 100680 Ploiesti, Romania
}

\begin{abstract}
Abstarct.Catalytic pyrolysis of the mucilages resulting from the refining of vegetable oil was performed under optimal conditions for obtaining a flux for road bitumen. The mucilage emulsion was stabilized in a reverse emulsion containing the lipid fraction with a sorbitol-polyethoxylated fatty acid ester type surfactant. The pyrolysis of the mucilages was carried out in a continuous system, in a quartz tubular reactor, positioned in the central area of a vertical furnace. The experimental program was performed in the presence of the $\mathrm{Cu}$ catalyst at atmospheric pressure, temperature in the isothermal reaction zone $520^{\circ} \mathrm{C}$ and liquid hourly space velocity of $0.5 \mathrm{~h}^{-1}$. The liquid fraction obtained was used to fluidize a road bitumen. The homogeneity of the fluidized bitumen was highlighted by determining the asphaltene content after its solidification.
\end{abstract}

Keywords: algal biomass, pyrolysis, coal, catalyst

\section{Introduction}

The accentuated industrial development was accompanied by a massive increase in the consumption of fossil raw materials; faced with the depletion of fossil resources and the impact of their use on the environment, the economy must find alternatives for raw materials. As a precursor to fossil raw materials, biomass is also composed of carbon and seems to be one of the best renewable solutions for replacing fossil resources in many applications. Renewable energy is a cross-cutting priority relevant to the development of the world economy. Thus biomass (including the biodegradable fraction of waste) is by far the most important renewable source of energy. Indeed, biomass can be used in energy applications for the production of heat, electricity and transport fuels, but also for the production of chemicals (food additives, pharmaceuticals, surfactants, organic solvents, fertilizers) etc. [1]. The use of biomass for these applications generally requires multi-stage conversions of the raw material. In order to develop such competitive processes, it is necessary to capitalize on the entire biomass content in the biorefines similar to those for the petroleum products. Among biomass recovery processes, its conversion by thermochemical methods seems to be a promising alternative for many energy applications [1].

Greenhouse gas emissions from biomass burning are not currently accounted for in any sector. So, in the short term, processing the biomass represented by wood waste or residues can allow considerable reductions in greenhouse gas emissions. Thus, the reduction of greenhouse gas emissions requires the predominant use of energy from renewable sources. Also, increasing the use of energy from renewable sources could reduce dependence on fossil fuels and energy imports, thus contributing to the security of energy supply. Statistical data confirm that biomass production in forestry and agriculture is increasing in absolute terms [2]. Thus the tendency for the production of bioenergy but also for the production of chemicals is to use only residual biomass and waste, ie biomass that would otherwise decompose. For example, in relation to the total quantity of fuels used in transport, the share

\footnotetext{
*email: gabi.vasilievici@gmail.com
} 
of energy obtained from "advanced biofuels", of liquid and gaseous fuels from renewable sources of non-biological origin, will increase significantly in the coming period.

The most current processes of thermochemistry are gasification, pyrolysis and combustion. All these procedures still require further research to improve their performance. Pyrolysis has proven to be a promising technique for converting biomass into fuel. In a recent paper [3] in situ catalysts were prepared by impregnating the biomass with $\mathrm{Ru}$ and $\mathrm{Fe}$ to study the kinetics of the pyrolysis process by thermogravimetric analysis (TGA). Weight loss was analyzed by TGA at four different heating rates $\left(5-20{ }^{\circ} \mathrm{C} * \mathrm{~min}^{-1}\right)$ over a temperature range of 30-900 ${ }^{\circ} \mathrm{C}$. Activation energy and pre-exponential factor for Ru-impregnated biomass had lower values than for Fe-impregnated biomass. Also the activation energy for the metal impregnated biomass was lower than for the raw biomass.

In a recent paper [4], the characteristics of pyrolysis and catalytic pyrolysis of three main components (hemicellulose, cellulose and lignin) of the biomass using a thermogravimetric analyzer (TGA) with a fixed bed reactor were investigated. The study aimed to understand the mechanism of pyrolysis, the kinetic reactions and the properties of the product obtained from biomass in order to select the agricultural and forestry residues suitable for generating the desired products. The results showed that the thermal stability of hemicellulose was lower than that of cellulose. The lignin decomposed over a wider range of temperatures and favored a higher carbon yield. Catalytic pyrolysis in the presence of the HZSM-5 catalyst favored conversion enhancement. The HZSM-5 catalyst improved reactivity and decreased activation energy in the following order: xylan> biomass> lignin> cellulose. Cellulose pyrolysis gave the highest yield of levoglucosan-rich bio-oil and other anhydrous sugars with minimal coke formation. Xylan gave a high yield of gas and a moderate yield of furfural rich bio-oil, while lignin gave the highest solid residue and produced the lowest yield in bio-oil that was rich in phenolic compounds. Following the catalytic pyrolysis process, xylan gave the highest yield of monocyclic aromatic hydrocarbons such as benzene and toluene. Cellulose showed higher selectivity for xylene and naphthalene.

In another paper [5] pyrolysis of some biomass samples was performed in the temperature range of $300-500^{\circ} \mathrm{C}$ to identify the optimum temperature for maximum bio-oil yield. GC-MS, FT-IR and $1 \mathrm{H}$ NMR analyzes revealed that the obtained bio-oils were rich in functional compounds such as phenolic compounds (2-methoxy-4-vinyl phenol, phenol, 2-methoxy, 4-ethyl phenol).

The production of pyrolysis oil from a biomass has been studied using a fluidized bed reactor using the rapid pyrolysis process [6]. The reactor temperature, surface velocity and feed rate of the feedstock were adjusted to obtain a high yield in pyrolysis oil. The results of this experiment revealed a maximum yield of pyrolysis oil of $36.93 \%$ at $480^{\circ} \mathrm{C}$.

In another study [7], waste clay impregnated oil was used as a raw material to produce high quality biofuel by catalytic pyrolysis. Thermal decomposition and pyrolysis of clay oil were studied. The influence of temperature, carrier gas flow, two types of catalyst (MCM-41 and $\mathrm{CaO}$ ) and the ratio of catalyst / clay oil on bio-oil compositions were studied. The optimum conditions for the production of high quality biofuels under catalytic regime were: temperature of $550{ }^{\circ} \mathrm{C}$, catalyst ratio of $1 / 5$ and carrier gas velocity of $0.1 \mathrm{NL} / \mathrm{min}$. CaO promoted the decarboxylation of residual clay oil and effectively improved the quality of the bio-oil. The acidity of the bio-oil obtained on the $\mathrm{CaO}$ catalyst was much lower than that of the bio-oil obtained in the absence of the catalysts, and the calorific power is much higher than that of the non-catalytic bio-oil and bio-diesel.

The types of biomass used in the study of the pyrolysis process are different. The published experimental data show that the process of pyrolysis of biomass is favored by the presence of catalysts. Typically either acid catalysts or metal catalysts are used. Acid catalysts usually have a higher efficiency, being used for a long time in many processes of crude oil processing, such as cracking, hydrodesulfurization, hydrotreating [8-12]. The main disadvantage of these catalysts is that they favor coke formation. In this study the influence of a $\mathrm{Cu}$-based catalyst on the pyrolysis process of a byproduct resulted in the refining of vegetable oils, respectively the residual fraction of mucilages, was studied. 


\section{Method and materials}

The mucilages used in experiments come from the refining of a sunflower oil. Its main characteristics are presented in table 1 . The density was determined according to ASTM standard D1298, the viscosity with Rotational Viscometers Raypa - RP1, the glyceride content from the saponification index and the lecithin content by the acetone precipitation method.

The surfactant used to stabilize mucilages suspensions are $20 \mathrm{EO}$ polyethoxylated sorbitan monooleate (Polysorbate 80 Aldrich - Tween 80). The emulsifier concentration in the prepared emulsions was $1.0 \%$ by weight and $3 \%$ respectively. Preparation of mucilages emulsions where carried out in a balloon fitted with a variable speed stirring system, at a speed of $2000 \mathrm{rpm}$. The stability of the prepared emulsions was determined with the help of a Turbiscan Lab.

Table 1. Characteristics of mucilages resulting from the refining of sunflower oil

\begin{tabular}{|c|c|c|}
\hline $\begin{array}{c}\text { No. } \\
\text { crt. }\end{array}$ & Component & Value, \\
\hline 1 & Density, $15^{\circ} \mathrm{C}, \mathrm{g} / \mathrm{cm}^{3}$ & 0.998 \\
\hline 2 & Viscosity, $15^{\circ} \mathrm{C}, \mathrm{mPa} \cdot \mathrm{s}$ & 14400 \\
\hline 3 & Water, \%wt & 62.46 \\
\hline 4 & Glycerides, \%wt & 28.59 \\
\hline 5 & Lecithins, \%wt & 8.95 \\
\hline & & \\
\hline
\end{tabular}

The $\mathrm{Cu}$ catalyst was prepared by precipitating from the nitrate solution of $\mathrm{Cu}$ with $\mathrm{KOH}$ at $\mathrm{pH} 10$, in the presence of Tween 80, to prevent agglomeration of the catalytic centers. Copper catalyst particle sizes and their size distribution were determined using a Dynamic Light Diffusion (DLS) particle size measurement system using a Malvern-Zetasizer NanoZS (Red Badge) instrument. The concentration of catalytic precursors to mucilages was $2 \%$ by weight.

The pyrolysis of the mucilage emulsion was carried out in a continuous system, in a quartz tubular reactor, positioned in the central area of a vertical furnace provided with an automatic temperature control system. The quartz tube had an inner diameter of $5 \mathrm{~mm}$ and a length of $50 \mathrm{~mm}$.

The pyrolysis experimental test was performed at the following operating parameter values:

- atmospheric pressure;

- temperature in the isothermal reaction zone: $520{ }^{\circ} \mathrm{C}$;

- liquid hourly space velocity (LHSV): $0.5 \mathrm{~h}^{-1}$.

The composition of the liquid fraction resulting from the pyrolysis was determined with a GCMS/MS TRIPLE QUAD (Agilent 7890 A) equipped with a DB-WAX capillary column (30 m length, $0.25 \mathrm{~mm}$ internal diameter, $0.25 \mu \mathrm{m}$ film thickness) and helium as carrier gas at one $\mathrm{mL} / \mathrm{min}$. The oven temperature was initially set at $70^{\circ} \mathrm{C}$ and then increased to $230{ }^{\circ} \mathrm{C}$ with a rate of $4{ }^{\circ} \mathrm{C} / \mathrm{min}$ and hold time of $5 \mathrm{~min}$. The GC injector and MS ion source temperatures were $250{ }^{\circ} \mathrm{C}$ and $150{ }^{\circ} \mathrm{C}$, respectively. The transfer line temperature was $280^{\circ} \mathrm{C}$. The MS detector was operated in EI mode at $70 \mathrm{eV}$, with a $\mathrm{m} / \mathrm{z}$ scanning range of 50-450. The FAME peaks in the sample were identified using NIST MS database.

For the preparation of fluidized bitumen, a road bitumen type D 50 / 70 was selected. The characteristics of the road bitumen type D 50/70 used in the experimental program are presented in table 2 . 


\section{Table 2}

Characteristics of the road bitumen type D $50 / 70$

\begin{tabular}{|c|c|c|}
\hline No. crt. & Component & Value \\
\hline 1 & Penetration at $25^{\circ} \mathrm{C}, 0.1 \mathrm{~mm}$ & 58.6 \\
\hline 2 & Softening point, ${ }^{\circ} \mathrm{C}$ & 47.3 \\
\hline 3 & Ductility at $25^{\circ} \mathrm{C}, \mathrm{cm}$ & $>150$ \\
\hline 4 & Breaking point Fraass, ${ }^{\circ} \mathrm{C}$ & -14.3 \\
\hline
\end{tabular}

The homogenization of the mixture of road flux and bitumen was carried out in a $250 \mathrm{~mL}$ autoclave provided with an anchor type shaker and a heating jacket.

\section{Results and discussions}

\section{Determination of stability of mucilage emulsions}

The evaluation of the stability of the prepared emulsions was carried out over a period of 10 hours, recording 11 curves for crude mucilage and mucilage emulsions with $1.0 \%$ and $3 \%$ Tween samples. The transmission and blackscattering profiles of mucilage emulsions ( $\mathrm{M}_{0}$ for crude mucilage $\mathrm{M}_{1}$ for mucilage with $1.0 \%$ Tween content and $\mathrm{M}_{2}$ for $3 \%$ Tween content respectively) are shown in Figures 1 -3 .

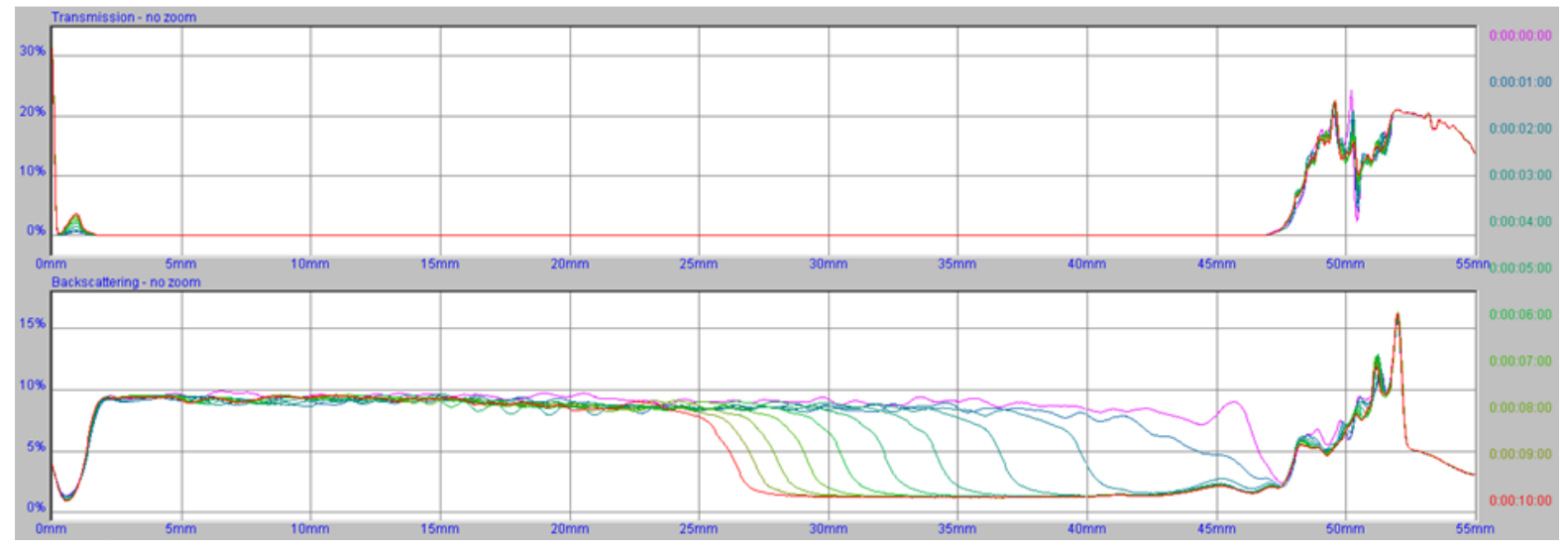

Figure 1. Stability profiles for sample $\mathrm{M}_{0}$

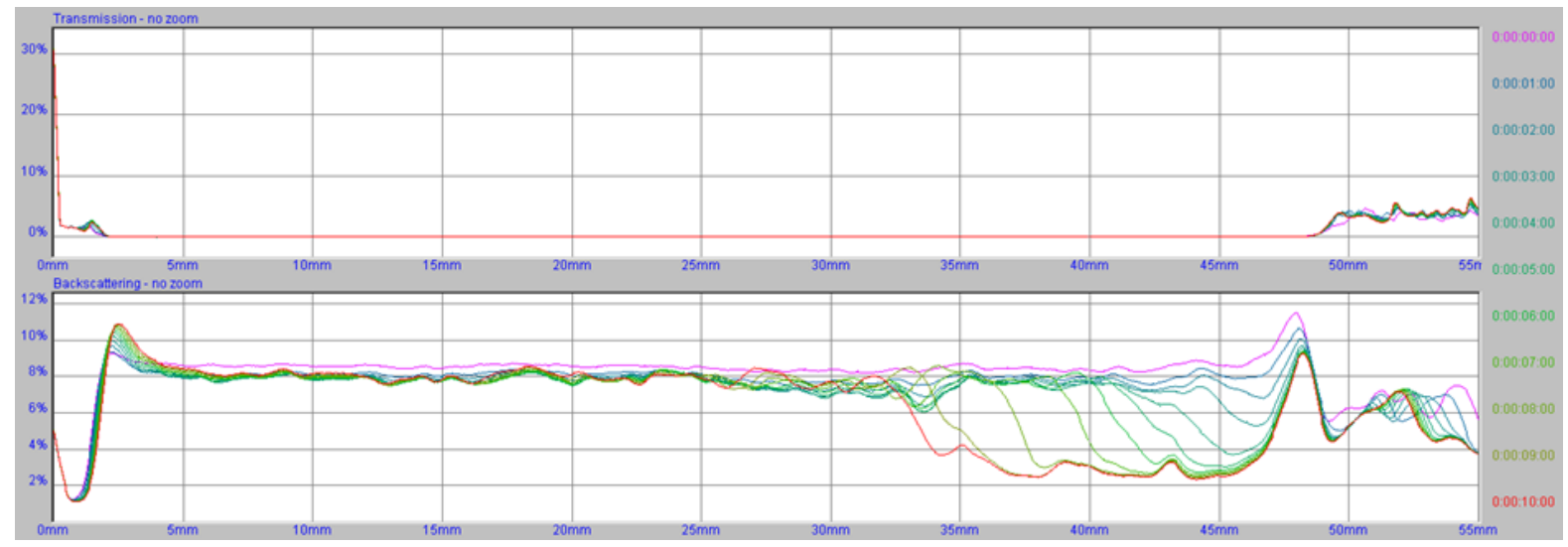

Figure 2. Stability profiles for sample $\mathrm{M}_{1}$ 


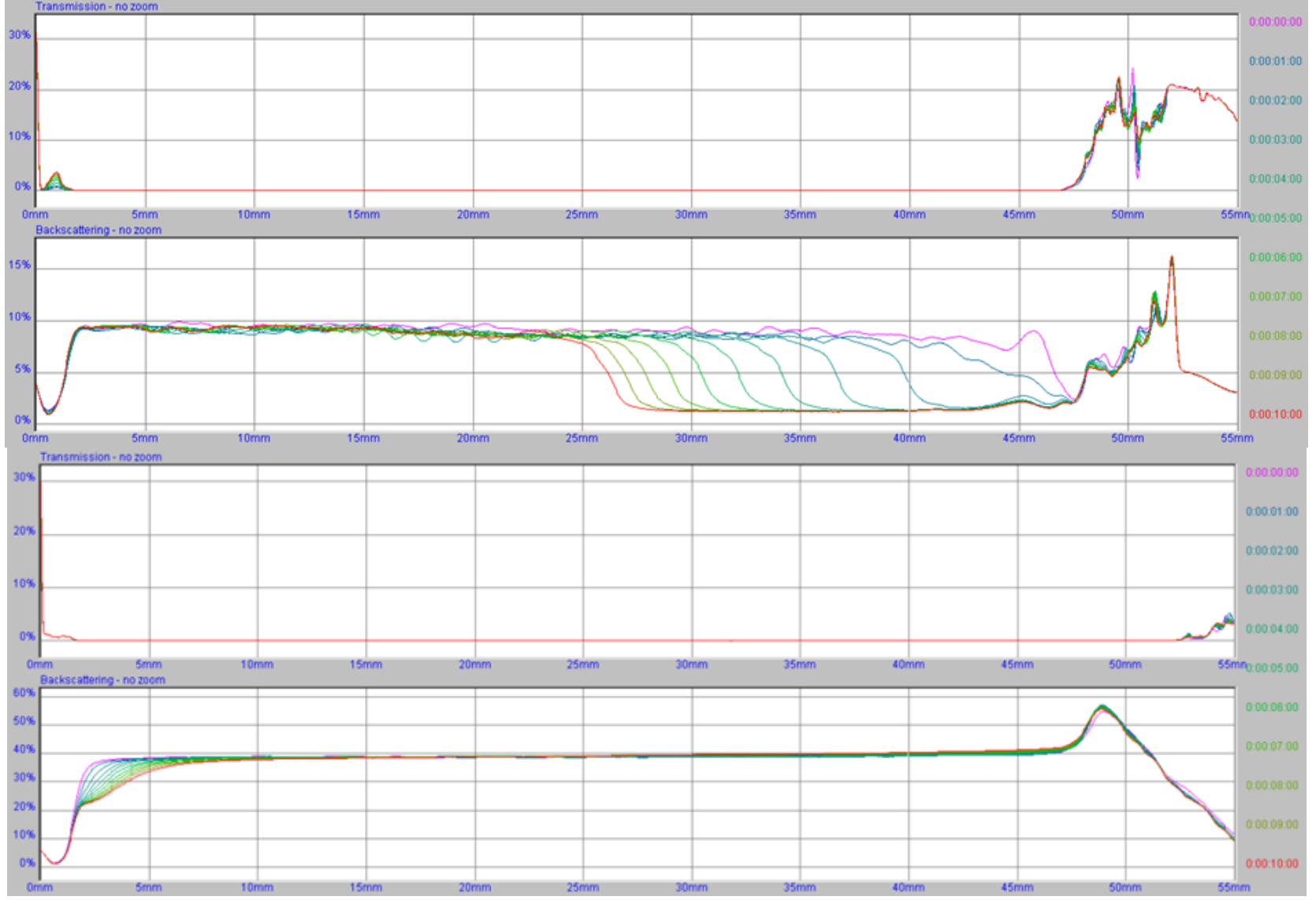

Figure 3. Stability profiles for sample $\mathrm{M}_{2}$

From the blackscattering curves it is observed that the stability of the mucilage emulsions has improved with the increase of the content in the Tween 80 emulsifier to $3 \%$ wt.

\section{Characterization of the catalyst based on $\mathrm{Cu}$}

The DLS analysis of the catalyst based on $\mathrm{Cu}$ is shown in Figure 4. From this figure it is observed that particles obtained after precipitation of $\mathrm{Cu}$ nitrate in the presence of Tween 80 have a unimodal distribution and an average copper particle size of $838.7 \mathrm{~nm}$.

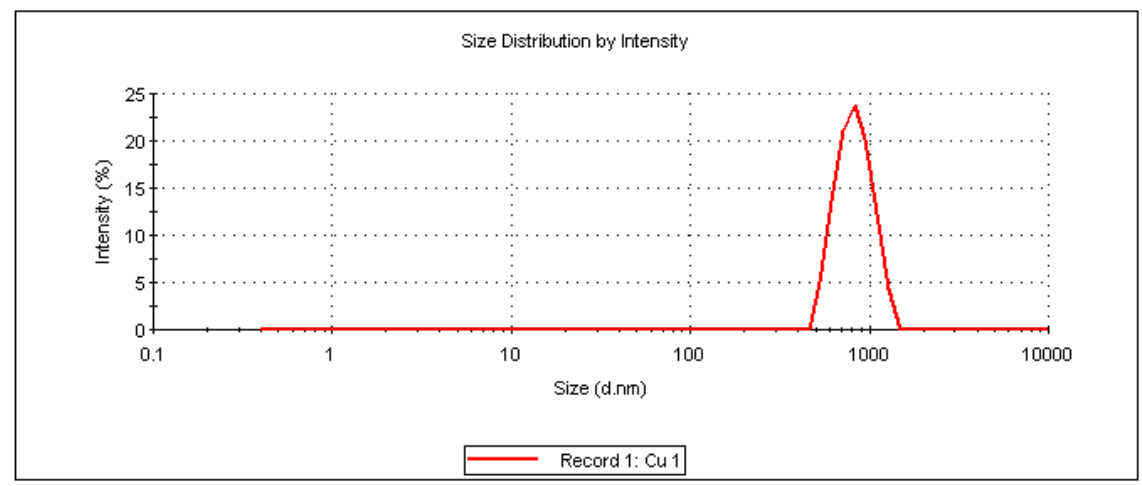

Figure 4. Distribution of the particle size of $\mathrm{Cu}$ catalyst precipitated in the presence of Tween 80 


\section{The pyrolysis experimental test}

Figure 5 present the chromatogram of liquid phase compositions separated during the catalytic pyrolysis process in the presence of $\mathrm{Cu}$ catalyst.

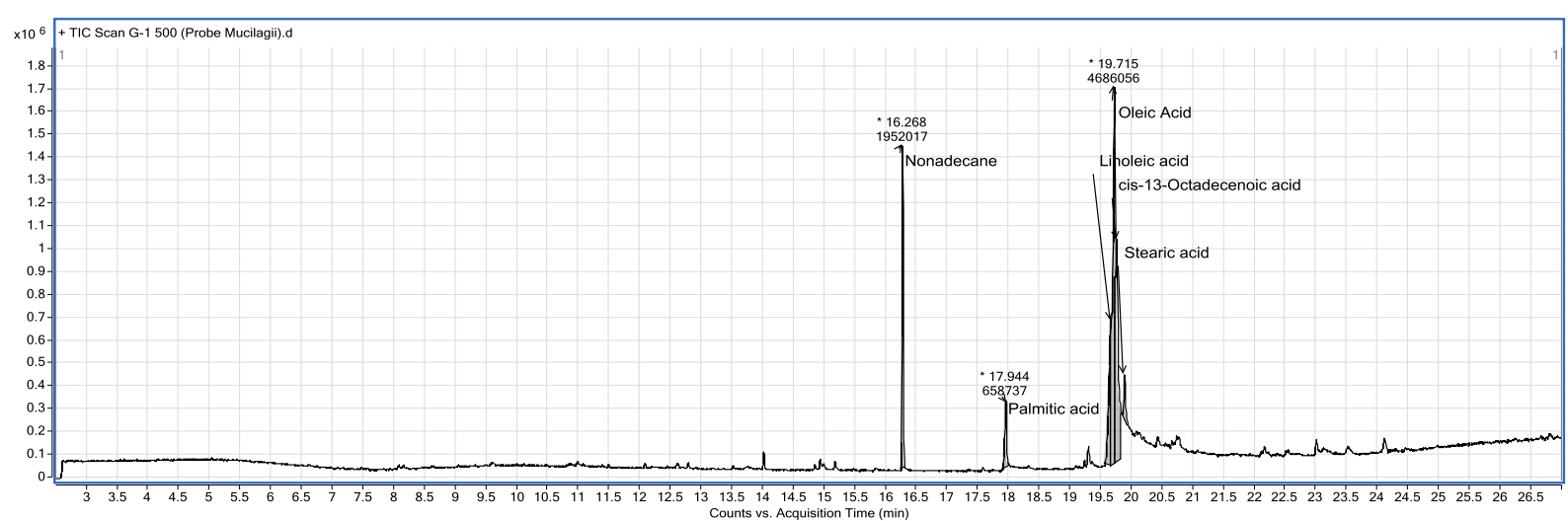

Figure 5. The composition of the organic liquid phase separated from the catalytic pyrolysis of mucilage

The chromatogram analysis shows the majority of unsaturated fatty acids and a low content of saturated fatty acids and linear aliphatic hydrocarbons (nonadecane). Thus, the content in linoleic acid was about $17 \%$, the content in oleic acid by almost $38 \%$ and the content in 13-octadecenoic acid by over $21 \%$ and the cumulative content in palmitic acid and stearic acid is approx. $8 \%$, while the content in nonadecan is less than $16 \%$. This composition promotes a good cold behavior of the fluidizer and its high reactivity over time.

The presence of nonadecane highlights the decarboxylation process as the main variant of cracking of mucilages, while the formation of fatty acids proceeds through the solvolysis of phosphatidic esters.

\section{Testing of the solvent prepared for the fluidization of road bitumen}

The fluidization of the bitumen was achieved by adding the fluidizer to the molten bitumen. Thus, $20 \mathrm{~g}$ of fluidizing obtained by pyrolysis of mucilages is introduced, in $100 \mathrm{~g}$ of road bitumen melted in the autoclave heated to $100{ }^{\circ} \mathrm{C}$, and the mixture is kept under stirring at a speed of $700 \mathrm{rpm}$, at $160{ }^{\circ} \mathrm{C}$ for $4 \mathrm{~h}$. Then the fluidized bitumen is cooled to a temperature of approx. $100{ }^{\circ} \mathrm{C}$ and inserted into a polypropylene tube with an internal diameter of $20 \mathrm{~mm}$, fixed in a vertical position, and fitted at the lower end. After cooling the fluidized bitumen, samples of flowed bitumen were collected from the two ends of the polypropylene tube in order to evaluate the homogeneity of the fluidized bitumen. The homogeneity test of the flowed bitumen was performed by determining the asphaltenes content from the road bitumen and from the two samples taken, applying the precipitation method in the presence of heptane. The asphaltenes content of the initial road bitumen and the fluidized bitumen are presented in table 3.

\section{Table 3}

Asphaltenes content of the road bitumen

\begin{tabular}{|c|l|c|}
\hline $\begin{array}{c}\text { No. } \\
\text { crt. }\end{array}$ & \multicolumn{1}{|c|}{$\begin{array}{c}\text { Asphaltenes content, } \\
\text { \%wt }\end{array}$} & Value \\
\hline 1 & Initial bitumen & 19.4 \\
\hline 2 & Fluidized bitumen from the upper area & 16.2 \\
\hline 3 & Fluidized bitumen from the lower area & 16.2 \\
\hline
\end{tabular}

The equal value of the asphalt content in the upper and lower areas demonstrates the homogeneity of the fluidized bitumen. 


\section{Conclusions}

The stabilization of the mucilage emulsion resulted in the refining of vegetable oil was achieved by re-emulsifying it in the presence of a nonionic ester type ester of fatty acids with sorbtol polyethoxylated. Thus, the stability of the mucilage emulsions has improved with the increase of the content in the Tween 80 emulsifier.

The pyrolysis of the mucilages emulsion was carried out in a continuous system, in a quartz tubular reactor, at $520^{\circ} \mathrm{C}$, liquid hourly space velocity of $0.5 \mathrm{~h}^{-1}$ and atmospheric pressure. The main processes that take place in pyrolysis of mucilages in the presence of the $\mathrm{Cu}$ catalyst are decarboxylation with the formation of linear hydrocarbons with an odd number of carbon atoms and solvolysis of the lecithins and glycerides present in this by-product with the formation of fatty acids.

The liquid fractions obtained contains compounds with optimum polarity for solubilizing the classes of compounds present in the road bitumen and for stabilizing its colloidal structure. Also, the low volatility of these compounds does not affect the aging characteristics of bitumen such as loss of mass and residual penetration; in addition the freezing point of most of these compounds does not affect the cold behavior of fluidized bitumen.

Acknowledgements: The authors gratefully acknowledge the financial support of the National Authority for Scientific Research and Innovation (ANCSI), Romania, project code POC-A1 A1.2.3-G2015 Project Type: Partnerships for knowledge transfer, ID /MySMIS: P_40_352 / 105684, financing contract no. 81/08.09.2016 and no. 3/3.01.2018.

\section{References}

1. COLLARD, F.X., BLIN, J., Renewable and Sustainable Energy Reviews, 2014, 38, 594-608.

2. *** http://ec.europa.eu/eurostat/statistics-explained/index.php/Agri-environmental_indicator__renewable_energy_production.

3. KUMAR, A.S.V., SIVAMOHAN, P. M., REDDY, N., Bioresource Technology, 2019, 285, in press.

4. ZHENG, Y., TAO, L., YANG, X., HUANG, Y., ZHENG, Z., Journal of the Energy Institute, 2019, 92, (5), p 1348-1363.

5. AWASTHI, A., SINGH, G., DHYANI, V., KUMAR, J., SUDHAKARA, Y.R., ADARSH, V.P., PUTHIYAMADAM, A., MULLEPUREDDY, K.K., SUKUMARAN, R.K., UMMALYMA, S.B., SAHOO, D., BHASKAR, T., Bioresource Technology, 2019, 285, in press.

6.SUNTIVARAKORN, R.,TREEDET, W., SINGBUA, P.,TEERAMAETAWAT, N., Energy Reports, 2018, 4, p. 565-575.

7. WANG, S., YUAN, C., ESAKKIMUTHU, S., XU, L., CAO, B., ABOMOHRA, A. F., QIAN, L., LIU, L., HU, Y., Journal of Analytical and Applied Pyrolysis, 2019, 141, in press.

8. DOUKEH, R., BOMBOS, M., MOLDOVAN, M., BOLOCAN, I., Rev. Chim., 69,(6), 2018, 1386

9. POPESCU (STANICA), A. I., BOMBOS, M., DOUKEH, R., BOMBOS, D., BOLOCAN, I., Rev. Chim., 67(3), 2016, 570

10. DOUKEH, R., TRIFOI, A., BOMBOS, M., BANU, I., PASARE, M., BOLOCAN, I., Rev. Chim., 69,(2), 2018, 396

11. DOUKEH, R., BOMBOS, M., POPOVICI, D., PASARE, M., BOLOCAN, I., Rev. Chim., 70,(1), 2019 , p. 27

12. DOUKEH, R., BOMBOS,M., TRIFOI,A., PASARE,M., BANU,I., BOLOCAN,I., Chim., 68,(7), 2017, 1496

Manuscript received: 10.09.2019 